\title{
Connectionism and dynamic systems: are they really different?
}

\section{Esther Thelen ${ }^{1}$ and Elizabeth Bates ${ }^{2}$}

1. Department of Psychology, Indiana University, USA

2. Department of Cognitive Science, University of California, San Diego, USA

\begin{abstract}
We propose that connectionism and dynamic systems theory are strong contenders for a general theory of development that holds true whatever the content domain. We illustrate, through our own career narratives, the origins of these theories in motor and language development. We situate connectionism and dynamic systems among other classic and contemporary theories and conclude that, although there are meaningful differences, these differences pale in relation to the shared assumptions about the fundamental processes and mechanisms of change.
\end{abstract}

Once upon a time, thanks to Jean Piaget, the field of cognitive development had a coherent, interesting, testable, and widely accepted theory. Now, alas, we are back in the preparadigmatic boat with our colleagues in the rest of psychology, with theory fragments, almost-theories, and pseudotheories bobbing about around us. ... I will try to differentiate several distinct possibilities for future theories.... Most probably each of these theories will turn out to be true of different aspects of development. ... For any particular developmental phenomenon, one theory or another will be true, and we want to know which one it is. (Gopnik, 1996, p. 221)

According to Alison Gopnik's vision of the postPiagetian era, the search for a grand developmental theory is futile. Piaget was wrong: broad, general explanations seem 'increasingly implausible' (p. 221) and efforts are better spent working out the details, domain-by-domain. The traditional big issues of developmental theory nature vs. nurture, continuity and discontinuity, modularity vs. distributed processes, and so on - should be cast aside in favor of specific theories about content.

While we agree about the importance of the details, we also believe that Gopnik, and others who espouse the domain-specific view, have scuttled the theoretical boat somewhat prematurely. In this special issue of Developmental Science we present a discussion of two contemporary contenders for the 'big picture': connectionism and dynamic systems theory. The articles are the result of a symposium held at the 2001 meeting of the Society for Research in Child Development. The large audience who attended the symposium presumably did not share Gopnik's pessimism over the future of developmental theory (although it is possible they came to witness the duel-to-the death!). Rather, we sensed a growing interest and excitement, especially as these new theories are implemented in mathematical models, and thus, make contact with similar theoretical enterprises in cognitive science, biology and neuroscience. Here we focus specifically on the question of whether we are dealing with one grand theory or two: how alike or how different are connectionism and dynamic systems?

To begin, we state forthrightly that we do believe that there are general principles of development: mechanisms and processes that hold true whatever the content domain. Moreover, we assert that researchers make theoretical assumptions about these processes and mechanisms whenever they design and conduct a study. Often these assumptions are implicit, but they influence every decision about the choice of variables, design, research population, sampling intervals and statistical technique. Good theory makes these assumptions explicit, and subjects them to empirical test. Furthermore, the role of formal models is to make these underlying assumptions extremely precise. The specific form of the model is thus less important than the general principles of development on which it is based.

We devote our introduction, therefore, to the developmental principles - the qualitative theory and assumptions - that form the bases for the two related approaches of connectionism and dynamic systems. We compare them to the assumptions of other general theories and discuss the strengths and weaknesses of each. Note that there is a not-so-subtle irony here. Neither author, Bates nor Thelen, has ever programmed a computer, written an original equation, or run a simulation. How did it come

Address for correspondence: Esther Thelen, Department of Psychology, Indiana University, 1101 East 10th Street, Bloomington, IN 47405, USA; e-mail: thelene@indiana.edu 
to pass, the reader may ask, that both of us are deeply committed to theories that rely on mathematics and computer modeling? How did we end up introducing this special issue of Developmental Science?

The answer to these questions takes on a somewhat autobiographical flavor. We apologize in advance for this self-indulgent exercise, but we believe it might be useful (for the purposes of this special issue) to consider how the two of us arrived at the theoretical positions that we espouse today. In our conversations during the preparation of this little paper, we have uncovered many similarities in the intellectual influences and experiences that led us to our current views. Some of these similarities may have the banality of a first date ('You like Chinese food too?'). But taken together, these similarities in our intellectual history provide additional support for the conclusion that we offer here: connectionism and dynamic systems should not be viewed as competing theories of development. Instead, we conclude that connectionism and dynamic systems are the same theory, approached with somewhat different methodologies and goals.

\section{Autobiography}

Although we both consider ourselves developmental psychologists, we are also grounded in biology, as well as psycholinguistics (Bates), and movement science (Thelen). From the beginnings of our careers, we were uppity young women who had strong theoretical biases (Bates, 1976; Thelen, 1981). In the service of those theoretical biases and the questions that they raise, we have both undertaken detailed, longitudinal studies to learn about the nature of change (Bates, Benigni, Bretherton, Camaioni \& Volterra, 1979; Bates, Bretherton \& Snyder, 1988; Bates \& Goodman, 1997; Thelen, 1979, 1985; Thelen, Corbetta \& Spencer, 1996; Thelen \& Ulrich, 1991). We did not begin with models and look for conceptual theory and data to fit to the models. Rather, we took the reverse course. We started with concepts and data that were made richer and more understandable by mathematics and models. Equations alone do not a theory make! Indeed, many of our foundational beliefs about development might be instantiated in different mathematical and computational formats. But the particular formulations of connectionism and dynamic systems have captured our core assumptions in particularly enlightening ways, opened up new avenues for empirical research, and allowed us to make connections between our developmental data and discoveries in the fields of cognitive science and neuroscience.

Our theoretical biases did not follow in any obvious way from our training. We both began our studies in the
American Midwest, surrounded by dustbowl empiricism in a period before the cognitive revolution had made its way inward from the two coasts. Perhaps for that reason, we were buffered from the formative effects of the initial revolution in generative linguistics and cognitive psychology, with its emphasis on the serial digital computer as metaphor for mind. We never embraced that metaphor. Instead, we were drawn from the beginning to the elusive notions of self-organization and emergent form. Each of us regards D'Arcy Thompson's On growth and form (1942) as perhaps the single most important influence on our views of mind and development. This classical work with its beguiling black-and-white drawings gave us a tantalizing glimpse into the union of biology and mathematics, and promised some avenues whereby complex structures might emerge from simpler beginnings. The other central influence for both of us was Piaget's Genetic epistemology (1970), a slim essay on the emergence of mind that was gracefully free of all the stages and logical formalisms that cluttered much of the work for which Piaget is remembered by others. Each of us therefore started our interest in Piaget from a purely epistemological perspective, as an implementation in child development of the emergentist notions illustrated by D'Arcy Thompson. We did not start with children and go on to discover Piaget. We did it the other way around, which has allowed us (or so we believe) to keep the best that Piaget had to offer, and to chart a course of our own in the study of development.

\section{Thelen's story: dynamic systems - from moving to developing}

I came to developmental psychology through my interest and training in behavioral biology. At the University of Missouri, where I did my PhD, I became fascinated with the ethologists' descriptions of 'fixed action patterns' or highly repeatable movements seen in birds and other animals. Inspired by my reading of Piaget, and the wonderful work of Peter Wolff (1968), I wondered about such rhythmical movements in human infants, and thus, to the nature of their control and development. This subsequently led to my interest in motor development and, more broadly, to issues in development in general. Thus, my views on dynamic systems as a developmental theory grew from struggles to make sense of my growing body of data on infants' early limb and body movements.

In the early 1980s there was little new work on early motor development. Traditional views about motor development were based on a maturational and hierarchical neural model. In particular, that newborn infants' movements were controlled by lower centers of the nervous system such as primitive reflex pathways and spinal 
pattern generators (e.g. Forssberg, 1985). Voluntary control awaited 'maturation' of the 'higher centers' over the first year. As the cortex matured, it would then both inhibit the more primitive movements and recruit them for voluntary actions. The picture was of a passive body and a passive infant awaiting autonomous maturational changes in voluntary control, which proceeded according to a genetically determined developmental plan. Thus, development was entirely 'top-down': the brain dictated movement and the genes built the brain.

I found these assumptions woefully incomplete to understand my observations of infant motor development. Several puzzling results challenged the conventional view. One puzzle emerged from my earliest work on 'rhythmical stereotypies'. These are the normal, but transient bouts of rhythmical movements performed by infants using their limbs and body segments that are common throughout the first year (Thelen, 1979). Detailed longitudinal studies revealed that rhythmical stereotypies using different body parts or postures emerged when infants were on the verge of having good voluntary control of that body segment or posture. For example, infants commonly rocked back and forth on hands and knees before they crawled and banged their arms before they acquired fine motor control. When first performed, the movements seemed without goal or purpose, but later, infants used them for a more directed goal such as social communication or to produce an interesting effect. For instance, arm-waving became banging on the table to make a noise. Why do these movements appear when they do? How do they change? Why do they disappear? Why the particular rhythmical form?

The second puzzle was the now well-known story of the disappearance of the so-called newborn 'stepping reflex' (Thelen \& Fisher, 1982). The old view was that infant stepping was inhibited as cortical centers autonomously matured. Donna Fisher and I provided a more 'peripheral' explanation: infants' legs simply grew heavy with subcutaneous fat, making it impossible to lift them when infants were supported upright. This meant that movement patterns were constituted from more than just their neural underpinnings.

The third puzzle concerned the nature of the control of such rhythmical movements, and kicking in particular. Leg kicking is a particularly well-structured and rhythmical movement seen from the first days of life. From the traditional view, kicking was a manifestation of spinal circuits later used for locomotion. But Fisher and I (Thelen \& Fisher, 1983) discovered that the neural signals were highly underspecified in relation to the patterns of joint coordination and the constrained timing. We found that the rather precise cycles of flexion and extension were produced by undifferentiated patterns of muscle activation: flexors and extensors activated during leg flexion, but extensions came from the passive, springlike qualities of muscle in a flexed leg. Again, coordination and timing were emergent properties, not specified by neural signals alone.

Infant treadmill stepping posed yet a fourth challenge to traditional accounts. Infants of 3 to 8 months of age do not make stepping movements when they are held upright. However, when I (Thelen, 1986) supported these infants on a small, motorized treadmill, they produced remarkably well-coordinated and alternating stepping movements, which were quite similar to later locomotion. The movements were not simply reflexive, as infants adjusted the speed of their steps to the speed of the treadmill, and even maintained alternation when each leg was placed on half of a split-belt treadmill with the belts moving at different speeds. This demonstrated that the source of these precocious movements was not solely 'in' the infant in terms of a fixed motor program or set of reflexes. Nor was it 'in' the treadmill, a mechanical device. Rather infant treadmill stepping was truly emergent from the particular confluence of circumstances that included the infant in interaction with the movement of the treadmill.

It seemed clear from the treadmill and the other examples that the nervous system is only one component contributing to infants' movement patterns. Infants' body weights and proportions, postures, elastic and inertial properties of muscle and the nature of the task and environment contribute equally to the motor outcome. Moreover, infants seemed to be exquisitely sensitive to changes in the tasks, and able to 'self-assemble' new motor patterns in novel situations. Sometimes, as in infant stereotypies, the movements seemed 'attracted' into a cyclic repetition, oblivious to any apparent goal. Developmentally, change seemed not so much the stagelike progression of new accomplishments as the waxing and waning of patterns, some stable and adaptive and others fleeting and seen only under special conditions. Some contexts, like the treadmill, revealed components of actions available long before the full behavior appeared, suggesting that the full-blown skill is awaiting the confluence of many elements and that these elements change asynchronously. What, then, is the fundamental nature of movement and its development? Do these observations fit under a unified theoretical umbrella?

\section{Dynamic systems theory}

My evolving developmental theory actually grew out of a theory of action. At about the time I was puzzling over infants' legs, scientists at the University of Connecticut published two chapters that revolutionized the way 
people conceptualized human movement (Kelso, Holt, Kugler \& Turvey, 1980; Kugler, Kelso \& Turvey, 1980; see also Turvey, 1977; Turvey, Shaw \& Mace, 1978). The 1980 papers were complex and densely argued, using concepts from movement science, biology, thermodynamics and nonlinear dynamics, and they stood in stark contrast to the other chapters in the same volume, which were largely centered on engineering, information processing and control theory models. The chapters began by posing the question asked by $\mathrm{N}$. Bernstein (1967), the pioneering, but yet little known, Soviet movement scientist. Bernstein noted that the moving body possessed many independent 'degrees of freedom' in the potentially controllable number of joints, muscles and neurons. The computational load of controlling so many degrees of freedom is enormous. How, then, Bernstein asked can these degrees of freedom 'be regulated in the course of activity by a minimally intelligent executive intervening minimally?' (Kugler et al., 1980, p. 4). Bernstein's solution was that movements are organized into functional groupings or synergies, flexibly adapted by people to meet specific tasks. Moreover, as these synergies are assembled, they also take advantage of the nonneural aspects of movement: effects of gravity, elastic properties of muscles and inertial effects. This optimal use of 'passive' movement also lightens the computational load.

The contribution of Kugler et al. (1980, also see Greene, 1982) was to conceptualize the assembly of movement 'coordinative structures' as a special kind of thermodynamic system, a nonlinear, 'dissipative' system that used energy to maintain complexity. Such physical and biological structures literally 'self-organize' to form patterns: that is, the individual parts, none of which contain any program or blueprints, produce a more complex organization as a result of their interrelations. Thus, when the many, heterogeneous elements that produce movements - nerves, muscles, joints, metabolic processes - cooperate together in a task, they cohere together in a way that is more complex than the sum of the parts.

Here was a brilliant solution to Bernstein's degrees of freedom problem. Rather than the degrees of freedom being a curse, a computational load to be overcome, they become the very source of organization and indeed, of change. Patterns emerge from the complexity of the system and its energetic status. As such, no component or element has priority or privilege, since it is the particular coalition of elements from which coherence arises. Thus, movements need not be 'represented' in the nervous system in all their detail. The details are created in their assembly.

The key metric of such dynamic systems is their stability, or the strength of the 'attractors' of their patterns.
When patterns self-organize, they settle into preferred states, which can be either quite stable, or unstable and easily perturbed. When patterns are stable, the elements cohere and resist change. For patterns to change, the system must lose stability: internal or external elements must disrupt the coherence so that the components can reorganize into a new and more stable state.

A classic example in motor behavior is the transition between gait patterns seen in many quadruped animals. As, say, a horse, increases the speed of its locomotion, it shifts spontaneously from a walk, to a trot, to a gallop. The transitions are nonlinear because not all increases in speed are equally effective in creating a shift. Patterns change only at critical values, and then they do so rather suddenly, without intermediate patterns. Experimental studies of other rhythmical movements have documented that system change is preceded by loss of stability indexed through increased fluctuations or variability in the system components. In this way, movements can be seen as 'softly-assembled' patterns created and dissolved as tasks and environments change, with some patterns easy and preferred, and others more difficult and unstable.

Moreover, Kugler et al. (1980) noted that oscillation or cyclicity was one common attractor of such biological systems. Like a physical pendulum, such systems use a 'squirt' of energy to maintain continuous, periodic patterns. For instance, in normal locomotion, active muscle contraction is used in only parts of the cycle - the rest of the movement, like that of the pendulum, is the product of the self-organized ensemble of the neural, elastic, inertial properties of the components.

To learn more about these new views, I spent the summer of 1983 at Haskins Laboratories with Scott Kelso, who patiently tutored me in this powerful way of understanding movement. Later, discussions continued with Kelso and with Gregor Schöner, Kelso's young physicist collaborator, who himself had been trained by the Nobel physicist Hermann Haken. At that time, Kelso and Schöner were using dynamic models to describe the now-classic phase transition experiments in bimanual coordination (Kelso, 1995). These mentors continually impressed upon me the need for a tractable 'model system' to work out dynamic principles and for a close dialogue between model and experiments. But in the early 1980 s no one could see how to bring this level of mathematical precision to infant behavior, which was variable, non-stationary, and difficult to put under very precise experimental control.

Even without formal models of infants, dynamic systems ideas gave me a remarkably useful framework for situating my discoveries about early infant movement and for designing new experiments. Early infant rhythmicities could be envisioned as 'softly-assembled' and 
transient patterns which naturally oscillate, and which infants perform during transition times when they can recruit particular coordinative patterns, but are yet unable to use them for intentional goals. Furthermore, as with leg kicks, the patterns are self-organized in that the ensemble is more complex than the neural signals that accompany it. Treadmill stepping showed, in addition, that the environment was as much a part of the selforganized system as the organism because the treadmill was essential to complete the stepping pattern. In short, viewing infant movements as nonlinear, dissipative, complex thermodynamic systems provided much more explanatory power for real behavior than the conventional top-down, neurologically driven alternatives.

\section{From movement theory to developmental theory}

The generation of an action - a step or a reach or the swing of a baseball bat - is a change of form over time. The organism moves from one state to another continuously, as a coherent ensemble of the participating components. Likewise, development is a change of form over time, albeit a longer time, and also produces behavior that condenses many degrees of freedom. I realized that the same principles of change applied to this longer time scale. Just as real-time states must lose stability to shift to new forms of action, so also must preferred patterns of behavior lose stability to engender developmental change.

Of course, the notion that equilibration and disequilibration are the fundamental processes of developmental change is not new. It is the heart of Piagetian theory, and many others. The contemporary version, as dynamic systems theory, adds several features to the older formulations. First, it explicitly connects this form of biological change to the more general principles of complex dynamic systems. Second, I have emphasized the coalitional nature of the collective state, such that no one component of the system is privileged, allowing new forms to be engendered by shifts in any part of the system, including those psychologists usually deem peripheral such as bodily changes. Third, and related to this, is the emphasis on 'soft-assembly' of patterns for a particular task. There are no inferences about unobservable mental structures that exist outside of the behavior-incontext. This assumption does away with the distinction between 'competence' and 'performance' that has plagued recent research. Dynamic systems theory says it is not useful to ask what a child 'really knows' because there is only behavior assembled to do tasks: behavior that may be stable over many tasks, but can also be fragile under other circumstances. A fourth difference is the blurring of the distinction between 'learning' and 'development'. An organism's ongoing activity continu- ally changes its neural states, just as growth changes the physical dimensions of the body. Some changes occur rapidly, others over many months or years. But there is no way to parcel these changes into different processes called 'learning' or 'development' because they seamlessly meld into each other. Every new state depends on the states that preceded it. In the fifth place, the ideas of 'soft-assembly' and historical contingency offer a way of conceptualizing both the global and universal changes in development as well as the local, variable and individual pathways. Finally, and importantly, the mathematics of dynamic systems provide tools to make these assumptions very precise and to generate simulations and predictions that can then be tested with experiments.

My work was immensely broadened by my move to Indiana University in 1985. Soon after my arrival, a group of faculty began meeting regularly to read and discuss dynamic systems ideas. This nucleus included Linda Smith and Geoff Bingham from Psychology, Bob Port from Linguistics, Tim van Gelder from Philosophy, and Mike Gasser from Computer Science. It was an exciting time. As we began to explore the implications of dynamic ways of thinking in their various domains, we saw the possibilities of a real paradigm shift in cognitive science, a shift that has indeed begun. My collaborations with Smith were especially fruitful for expanding dynamic systems ideas into more generally cognitive domains, and our work together resulted in two books (Smith \& Thelen, 1993; Thelen \& Smith, 1994). As a result of these meetings, Port and van Gelder (1995) also edited an important collection of dynamic systems papers published under the wonderful title, Mind as motion.

In our 1994 book, Smith and I set out to both ground a general theory of development in sensorimotor behavior and to extend the ideas to the 'harder' problems of cognition, especially categories and language, Smith's areas of research. As a demonstration of this new way of thinking, we chose to reinterpret a classic task in cognitive development, Piaget's 'A-not-B' task. The point of our qualitative model was to show how behavior that has been traditionally interpreted as a manifestation of a purely mental concept - that of the permanence of objects - could be understood as emerging from the dynamics of the reaching task itself, including the history of previous actions. We were so intrigued by the possibilities of the A-not-B task as a model system for dynamic emergence, we held a small workshop about it. We brought together diverse scholars to discuss this single phenomenon - dynamic theorist Gregor Schöner, connectionist pioneer Jay McClelland, movement scientists Marc Jeannerod and Mark Latash, developmental psychologist Elizabeth Spelke and neuroscientist Giuseppe Pelizzer. This unique discussion and the subsequent extraordinary 
collaboration with Schöner led both to the powerful mathematical model of A-not-B (which Schöner adapted from his more general model of motor planning) and to our many experiments to test and amplify the model (see, for instance, Smith, Thelen, Titzer \& McLin, 1999; Thelen, Schöner, Scheier \& Smith, 2001).

As reported in this special issue (Spencer \& Schöner) the A-not-B task has also provided the means to take dynamic approaches beyond motor systems and overt behavior to considering the dynamics of mental activities as well. Indeed the A-not-B model is a very general model of decision-making that might be applied to other tasks. Overall, a strength of the dynamic approach is that the same general principles can be applied across many levels of analysis and across many time scales. In addition, there are many different mathematical instantiations of dynamics. I have followed in the tradition of Haken's synergetics (Haken, 1977) and the more recent work was inspired by the dynamics of Amari (1977). In contrast, van der Maas and Molenaar (1992) used socalled 'catastrophe theory' to model Piagetian stage-like development. Van Geert $(1994,1998)$ pioneered the adaptation of classic, ecological growth models to simulate the dynamics of language and cognitive development. Here the basic assumption is that the system is a collective of 'growers' that have both cooperative and competitive nonlinear interactions. Similarly, Fischer and colleagues (Bidell \& Fischer, 2000) have adapted these growth models to skill theory development, emphasizing the role of variability in qualitative change. Others have used dynamic principles to study social development (Lewis, Lamey \& Douglas, 1999) and even social policy relating to children (Yoshikawa \& Hsueh, 2001). All of these approaches share assumptions of coalitions leading to self-organization, nonlinearity and emergence, although they may differ in their emphasis on mental structures. Finally, although dynamic approaches to development have not been explicitly neuroanatomical theories, and they make no assumptions about realistic connectivity in the nervous system, they are entirely compatible with formulations of the collective activity of the brain (Bastian, Riehle, Erlhagen \& Schöner, 1998; Kelso, 1995; Koch \& Davis, 1994; Sporns \& Edelman, 1993). What began as a way of understanding movement has become a way of understanding many aspects of human behavior and its development.

\section{Bates' story: connectionism - from interaction to language}

I began my formal studies at Saint Louis University, a Jesuit university where I acquired little expertise in experimental psychology but was strongly influenced by courses on philosophy of language and philosophy of mind. An abiding interest in language as a psychological process was cemented when I spent a year abroad in Italy, acquiring imperfect control over Italian but a lifelong devotion to the process of language learning (and to the people who surrounded me at the time). Having expressed an interest in 'finding out how the mind works and how we learn language', I was advised by my undergraduate professors that these interests were best pursued in clinical psychology. I began a $\mathrm{PhD}$ program in clinical psychology at the University of Connecticut, where I was first exposed to cognitive psychology (from Michael Turvey), psycholinguistics (from Alvin Liberman), language development (from David Wicklund) and speech perception (from Liberman and from Terry Halwes). With this exposure one might have expected a quick entrance into the prevailing views in that time and place, regarding 'special' innate mechanisms for speech and language. But the fledgling Gibsonian movement (evident in early Turvey) and James Jenkins' constructivist views (via Halwes and other Jenkins' students) had more impact, and I began to think about language learning as an active process of construction within a structured world. In my effort to escape from clinical psychology into the cognitive wing of the department, I adopted the department's Personality Theory major as a bridge, initiating research on individual differences in language processing in relation to established work on individual differences in cognitive style. This emphasis on individual differences has remained an important part of my research program, though it was not then and is not today a mainstream interest for most psycholinguists.

After two years at Connecticut, I transferred to the University of Chicago Committee on Human Development. In the elastic and tolerant atmosphere of that university, I was able to put together a program of studies that (in retrospect) bears some resemblance to cognitive science programs around the country today, with coursework in linguistics (especially generative semantics, an ancestor of today's cognitive linguistics), anthropology (under the guidance of Robert Levine, an expert in cross-cultural psychology who encouraged my interest in cross-linguistic comparisons), computer science (with strong intellectual and personal guidance from Peter Greene, also cited by Thelen as an early influence on her thinking about motor systems) and developmental psychology (including courses with Carol Feldman and David McNeill). An early interest in gesture and its relation to language development was born in coursework and conversations with $\mathrm{McNeill}$, who was just beginning his own research interests in that area. An interest in pragmatics and the functional analysis of language was strongly inspired by Feldman, who also provided guidance 
on Piagetian theory as a framework for the construction of mind.

After completing other requirements, I obtained some meager but adequate fellowship funding and returned to Rome to carry out a dissertation on the acquisition of Italian (culminating in my first book, Language and context, 1976). At the Institute of Psychology of the National Council of Research in Rome (IP/CNR), I began a series of collaborations with Virginia Volterra, Luigia Camaioni and other developmental psychologists on cognitive and communicative precursors and correlates of early language learning (see especially Bates, Camaioni \& Volterra, 1975). I have maintained and extended these Italian collaborations since that time, and am still a regular visitor.

The central idea of Language and context and in all of my writings since that time is the notion that grammars (in all their varying forms from one language to another) represent emergent solutions to a complex communicative problem: how to map from a rich, high-dimensional set of universal meanings onto a limited, low-dimensional channel of expression. (In many ways this is equivalent to the 'degrees of freedom' issue in movement science see Thelen's story, above.) D'Arcy Thompson's influence was obvious (at least to the author), but Piaget's epistemological framework played a more detailed role in the developmental scenario that we proposed in our early work, as follows.

Within the framework that we proposed at that time, the child spends her first 1-2 years constructing a universal set of meanings (along the lines specified in Piaget's theory of sensorimotor development), but she does so within a highly interactive social framework, and is motivated to communicate within that framework long before she can use linguistic symbols for that purpose. Gestural communication provides a window into the transition from preverbal to verbal communication, and gestural symbols (e.g. recognizing an empty cup by executing a conventional drinking gesture) can be observed to accompany the child's first efforts to convey the same meanings in speech (Bates et al., 1975; Bates et $a l ., 1979)$. In our view (then and now), the subsequent move into grammar (including the specifics of Italian compared with English) is still yoked to developments outside of language (e.g. the capacity to string two symbols together in a single complex act, reflecting what might be called 'working memory' today). However, grammatical development is best viewed as an intensely bidirectional process, involving movement from 'outside to inside' (inductive learning) as well as movement from 'inside to outside' (as the child seeks ways to express ideas about agency, location, negation, desire, evaluation and so forth).
In 1974, I took up my first faculty position at the University of Colorado, Boulder. The same year, Brian MacWhinney accepted a position at Denver University, fresh from completing a dissertation on the acquisition of Hungarian. MacWhinney and I shared common influences and similar theoretical biases that eventually led us both directly into the connectionism movement. We were both committed to cross-linguistic comparisons as a strategy for separating universal and languagespecific aspects of development (MacWhinney was a student of Berkeley's Dan Slobin, who also had a powerful if less official influence on my own work). Both of us were heavily invested in a functionalist approach to language and were influenced by linguistic theories that embodied such an approach (from yesterday's generative semantics to today's usage-based functionalist theories). This emphasis on functionalist approaches to language placed us outside the mainstream in linguistics and psycholinguistics, where emphases on innateness and autonomy of grammar still prevailed. Finally, MacWhinney and I shared a belief that the competence-performance distinction within linguistics was deeply misleading. We sought instead to explain linguistic variability (both cross-linguistic and individual differences) by building statistical variation directly into the representations that subserve language use. In other words, we argued that linguistic knowledge was 'probabilistic all the way down', reflecting the statistics of language use (in the input) and language learning (through inductive learning).

These shared biases started out as nothing more than that, hunches about how to conduct and interpret crosslinguistic studies of language learning. We began with comparative studies of English, Italian and Hungarian, but as the snowball rolled down hill we collected a large list of talented collaborators around the world interested in applying the same experimental techniques (e.g. Antonella Devescovi, Michelle Kail, Csaba Pleh). From early on, we complemented our studies of language comprehension and production in children with corresponding studies of adult controls, and found so many striking cross-linguistic differences in adults that our work began (and continues to this day) to reflect an equal balance of child language and adult psycholinguistics.

In an attempt to flesh out our initial hunches into a working model of language learning and language use, we and our colleagues developed the Competition Model, an interactive-activation theory of the process by which forms are mapped onto functions, and vice versa. The representational component of that model is probabilistic to its core: multilayered, many-to-many mappings between form and function, with mappings or 'cue strengths' gradually weighted across the course of development to reflect quantitative as well as qualitative variations 
in form-function mapping in the adult language (i.e. 'cue validity'). The acquisition of form-function mappings is strongly guided by cue validity, but mitigated by a third construct called 'cue cost', which refers to the processing costs incurred as the child or adult tries to make use of linguistic information (e.g. differences in the amount and kind of memory required, perceivability of the signal, amount of planning required for retrieval and articulation).

The Competition Model was based on our shared and core beliefs about language and how it develops: (1) that it is function-, rather than rule-driven; (2) that language acquisition is highly bidirectional and multilayered; (3) that language is learned from the input in a statistical or probabilistic way; and (4) that language learning is nonlinear, whereby gradual changes can lead to emergent properties. The parallels between the Competition Model and present-day connectionism are striking, in particular the emphasis on (1) distributed representations, (2) probabilistic links among nodes within those representations, (3) strengthening or weakening of links to reflect success or failure of predictions during comprehension (the basis of learning), (4) the nonlinear nature of the system and (5) the sometimes-surprising reorganizations that can result from these nonlinearities.

As MacWhinney has stated many times in the past, the Competition Model was a "paleo-connectionist theory'. In fact, the model has now merged directly into the river of connectionism that came by after the authors' first fledgling efforts to work out a theory of this kind (see MacWhinney \& Bates, 1989, for details of both history and substance; for additional details applied to the early stages of language development, see Bates, Thal \& Marchman, 1991). This merger was all but guaranteed by additional historical facts: in 1981, MacWhinney transferred to Carnegie-Mellon University (which was to become a future bastion of connectionism), and I transferred to the University of California, San Diego, where Rumelhart, McClelland and colleagues were developing a general purpose, multilayered, nonlinear neural network approach to cognition and learning (Rumelhart, McClelland and the PDP Research Group, 1986). In their foreword, Rumelhart and McClelland give me credit for the beehive metaphor of emergent structure, a matter of some embarrassment since I stole that metaphor from D'Arcy Thompson (who borrowed it from Bonanni). In contrast, I was not credited for what I view as my most important (and perhaps only) contribution to the new connectionist movement: constant hectoring of Rumelhart and McClelland to tackle some central problems in language development, including acquisition of the English past tense and the U-shaped phenomena observed in that process (Rumelhart, McClelland et al., 1986).
MacWhinney went on to conduct his own connectionist simulations of lexical and grammatical learning. In contrast, I continued to pursue behavioral studies of language processing and language development within an interactive-activation framework, including extensions to adults and children with unilateral brain injuries or other forms of neurological impairment. The goal was the same: to understand the emergence (not just learning, and certainly not just innate unfolding) of language by examining learning and use under a range of contrasting processing conditions - across languages, across individuals, across age levels and across pathological conditions (e.g. Bates, 1991; Bates, Thal, Trauner, Fenson, Aram, Eisele \& Nass, 1997; Dick, Bates, Wulfeck, Utman, Dronkers \& Gernsbacher, 2001).

The final bit of intellectual biography (at least for our purposes here) came in the first part of the 1990s. With a grant from the John D. and Catherine T. MacArthur Foundation, Jeff Elman and I (colleagues in the new UCSD Department of Cognitive Science) put together a training program in connectionist modeling for developmental psychologists. Among the many junior and senior developmentalists who passed through that program were Mark Johnson, Annette Karmiloff-Smith, Domenico Parisi and Kim Plunkett. Elman led the six of us in the preparation and writing of Rethinking innateness: $A$ connectionist perspective on development (1996). The theoretical architecture and empirical database reported in that book were themselves the result of parallel distributed processing, a lengthy process (five years from conception to publication) but one that proved extraordinarily fruitful for the six authors and (hopefully) for at least a subset of their readers. We offered the field of developmental psychology an opening bid: the rough outline of a new developmental framework based on principles of learning and representation from connectionism, synthesized against new results on plasticity and experiential effects on brain organization from developmental neurobiology (for a more recent update on applications of connectionisim to developmental psychology, see Bates \& Elman, 2002). The principles laid out in Rethinking innateness are compared with principles laid out in the Thelen-Smith volumes in the concluding section below, where we try to compare our perspectives with each other and with some of the 'grand traditions' in developmental psychology, along several different theoretical dimensions.

One final point of comparative autobiography regards the different climates in which Thelen and I were working out our views. Thelen was dissatisfied with a prevailing hierarchical view regarding motor systems that had no single personality or school associated with it. In contrast, those of us who tried to apply connectionism 
to language development have found ourselves in a rather different position, at odds with a hierarchical, predeterministic view of language within a strongly personalized and well-represented school of generative grammar. In the study of motor systems, there was a lot of concrete physics to work with, and considerable consensus about what might constitute a fact. In the field of language, the data often find it especially difficult to speak for themselves. It is perhaps not a surprise that the strongest attacks on connectionism have come from linguists and psycholinguists. The same individuals have shown much less interest in dynamic systems as a growing movement within developmental psychology. This is one more reason why it will be useful to consider similarities and differences between connectionism and dynamic systems: do we have the same opponents after all, and are the same issues at stake?

\section{Comparing theories of development}

We end this article with a didactic exercise that is open to extensive criticism. It represents our first-pass effort to compare axes of agreement and potential disagreement between connectionism and dynamic systems as theories of development, compared with a selected subset of major theories that guided research in our field throughout the 20th century. Table 1 summarizes similarities and differences among the following theories: Chomsky's $(1968,1975,1988)$ nativist theory of language development (which has inspired nativist theories in other domains as well - for a discussion, see Fodor, 1983), E.J. Gibson's $(1969,1988)$ theory of perception and perceptual development (which is certainly empiricist in emphasis), Vygotsky's (1978) theory of cognitive development within a social framework (a theory that is strongly empiricist in flavor, though it is certainly a complex and interesting exemplar of an empiricist approach), Piaget's $(1952,1970)$ constructivist theory of cognitive development (a direct predecessor to today's emergentist approach), and in relation to these four giants from the history of our field, connectionism (as laid out in Elman et al., 1996) and dynamic systems (as laid out in Thelen \& Smith, 1994). These six theories are compared regarding (1) the primary mechanism postulated by that theory to account for change, and regarding their relative emphases on (2) the structuring role of external information, (3) the importance of social interaction, (4) the role of biological constraints, (5) the use of information about brain development as a theoretical constraint, (6) emphasis on 'embodied cognition' (sensorimotor bases of higher cognition), (7) emphasis on and elaboration of mental representations, (8) invocation of dynamic systems as a source of causation/explanation of structure and change, (9) use of mathematical formalisms and (10) use of computer simulations as a tool for the study of development. In the brief review below, we assume that the reader is already familiar with all of these theories (i.e. this is not intended to be a 10-minute review of all of developmental psychology). We also assume that sophisticated readers will disagree with us on many of the classifications that we propose. At best, this little exercise should be viewed as an opening gambit, an invitation to discussion of the dimensions that separate major theories of development.

\section{(1) Mechanisms of change}

Chomsky invoked two related mechanisms to account for apparent change in behavior across the course of language learning: parameter setting and triggering. We use the term 'apparent change' because, in this account, nothing of any centrality appears in the course of development that was not already specified innately in the mind/brain and the genome that subserves them both. 'Triggering' refers to the release of a pre-existing behavioral

Table 1 A taxonomy of developmental theories

\begin{tabular}{|c|c|c|c|c|c|c|}
\hline Mechanisms of change & $\begin{array}{l}\text { Chomsky et al. } \\
\text { Maturation }\end{array}$ & $\begin{array}{c}\text { Gibson } \\
\text { Perceptual } \\
\text { Learning }\end{array}$ & $\begin{array}{c}\text { Vygotsky } \\
\text { Internalization }\end{array}$ & $\begin{array}{c}\text { Piaget } \\
\text { Construction }\end{array}$ & $\begin{array}{l}\text { Thelen/Smith } \\
\text { Self-organization }\end{array}$ & $\begin{array}{c}\text { Elman et al. } \\
\text { Emergence/ } \\
\text { Self-organization }\end{array}$ \\
\hline \multicolumn{7}{|l|}{ Emphasis on: } \\
\hline Experience & NO & YES & YES & YES & YES & YES \\
\hline External information & NO & YES & YES & YES & YES & YES \\
\hline Social interaction & NO & NO & YES & $\mathrm{NO}$ & $\mathrm{NO}$ & $\mathrm{NO}$ \\
\hline Biological constraints & YES & YES & NO & YES & YES & YES \\
\hline Brain development & $\mathrm{NO}$ & $\mathrm{NO}$ & NO & $\mathrm{NO}$ & YES & YES \\
\hline Embodied cognition & NO & NO & NO & YES & YES & NO \\
\hline Mental representations & YES & NO & YES & YES & NO (until after 1994) & YES \\
\hline Dynamical systems & NO & NO (yes) & NO & NO & YES & YES \\
\hline Formalization & YES & NO (yes) & NO & YES & YES & YES \\
\hline Computer simulations & NO & NO & NO & NO & NO (until after 1994) & YES \\
\hline
\end{tabular}


option by an environmental event (not unlike the triggering of the processes that lead to male genitalia in the embryo, brought about by the genetically timed release of testosterone). 'Parameter setting' is an enriched form of triggering, a process whereby children use environmental signals to select the correct parameters for their native language from an array of innate grammatical options. In elaborating these ideas over the years, Chomsky has consistently stressed that learning is highly overrated as a source of change, at least for those domains of behavior that are especially important for the species.

For Gibson, the primary mechanisms of change are children's exploration of their environment and the discovery of matches between their current abilities and the affordances for action inherent in a richly structured environment. This is primarily a process of perceptual learning, that is, an increasing ability to discern relevant features in the perceptual array and thus to tune actions appropriately to them.

Vygotsky built his theory on the notion of 'internalization'. For Vygotsky, many of the cognitive and linguistic structures that make us human are first played out in the realm of behavioral interaction with a competent adult. By participating in social interaction, the young organism moves from incompetence to competence, internalizing the relevant structures up to the point at which she can finally produce them on her own. Although this is a richer and more sophisticated form of environmental determination than one finds in many writings by many of Vygotsky's behaviorist contemporaries (American, European and Russian), internalization is certainly a mechanism that is 'pushed' from the outside.

Piaget's seminal contribution was his consistent emphasis on the bidirectional nature of cognitive development, a process of construction whereby children act on the world (assimilation) and then adjust their action schemata in accordance with their degree of success or failure (accommodation). The concepts of selforganization and emergence proposed in connectionism and in dynamic systems theory bear a strong historical relationship to Piaget's constructivism. Indeed, our differences with Piaget lie along other theoretical axes.

\section{(2) Structuring role of external information}

This axis is strongly correlated with the mechanisms of change just described, although it is not quite the same thing. Strongly nativist theories tend to downplay the structuring role of external information, while empiricist theories tend (by definition) to view the environment as a primary source of structure. Thus for Chomsky, the environment plays a limited role and acts primarily through triggering. Indeed, Chomsky has continually emphasized the paucity of the environment. For Vygotsky, in contrast, the social environment is a critical source of structure, internalized by the child through the process of social interaction. Likewise, for Gibson, the child does not need to build complex mental structures to represent the environment since the environment is already rich in information, only to be discovered. In this regard, Piaget continually emphasized the structured nature of the world in which the child exercises her minimal innate sensorimotor schemata, using information about a mismatch between her intentions and their realization (disequilibrium) to motivate change. However, the endpoint of cognitive development (formal operations) reflects a long series of transformations and reorganizations, resulting in structures that cannot be detected directly in the outside world in which the child has worked. External information plays a similar role in both connectionism and dynamic systems: external structure is critical, and a change in external structure may result in a completely different endpoint, but the endpoint itself is not 'contained' in the environment. However, connectionism has had a bit more to say about the relationship between external information and mental structure. With the advent of connectionism and associated simulations of the learning process, it has been possible to go into the 'hidden layers' (internal representations) that emerge across the course of learning, revealing end-point representations that often bear a very indirect relationship to the patterns that were input to the system.

\section{(3) Social interaction}

Of the six theories summarized in Table 1, Vygotsky's theory is the only one that has taken social interaction seriously as a source of structure in cognitive development. Chomsky denies that social factors play any important structural role in language development and Gibson does not assign any privileged status to social factors. Piaget often paid lip-service to the importance of social factors in the construction of mind (particularly in his works on language and culture - see Piaget's remarks on Vygotsky's views in Piaget, 1896). But it is fair to say that Piaget's emphasis always fell on the child as a lonely architect of mind, a small scientist working away on physical data. Both connectionism and dynamic systems have also neglected social factors as a source of structure in mental/behavioral development. But that is a matter of neglect rather than ideology. Because of their emphasis on external information as a source of structure, both theories are entirely compatible with socialinteractive accounts that emphasize the role of society in the construction of mind. 


\section{(4) Biological constraints}

Of the six theories in Table 1, Vygotsky's is the only one that had little or nothing to say about the role of biological constraints on development. We suspect this was an oversight of the same nature and magnitude as Piaget's neglect of social factors. In short, all serious developmental theories acknowledge the role of biology. They differ in the nature of the role, and the use (or not) of biological data.

\section{(5) Brain development as a source of constraints}

None of the four classic theories of development have made much use of information from developmental neurobiology. But to be fair, there was far less useful information available in the first $50-60$ years of the 20th century. In the last 20-30 years, there has been an explosion of information about plasticity, activity-dependent factors in brain development, and the bidirectional roles of both genes and environment in brain development (see esp. Chapter 5 of Elman et al., 1996; Chapter 5 of Thelen \& Smith, 1994). In our view, much of this information is incompatible with strong nativist theories (which emphasize a rigid form of biological determinism), and highly compatible with the kind of dynamic approach to development that we espouse. Hindsight is of course 20-20. Gibson, Vygotsky and Piaget cannot be blamed for ignoring information that was not available to them. We think, however, that today's nativists should take a closer look at the growing body of information about the bidirectional nature of brain and behavioral development. This is certainly a domain in which connectionist and dynamic systems theories are in strong agreement.

\section{(6) Sensorimotor bases of higher cognition}

Piaget's emphasis on the sensorimotor bases of higher cognition is the linchpin of his theory, and may be viewed as his most creative and important contribution. The same point is explicitly disavowed by Chomsky (who is committed to a grammar that is autonomous from the rest of mind, much less the body itself). It is implicit in Gibson's theory, but because of Gibson's strong critique of mentalism (see below), the idea was never fully developed. Vygotsky did acknowledge that sensorimotor factors play an important role in laying down the substrates of cognition (an asocial stratum of cognition that he referred to as 'tool thought'), but he gave these factors little role once language learning and socialization came into play. Dynamic systems theory, with its emphasis on perceptual-motor development, stands strongly in the tradition of Piaget in espousing the fully embodied mind. Connectionism is fully compatible with embodiment, but so far the developmental work has centered on internal changes in mental representations and not on the bidirectional influence of perception and action. The issue of embodiment and mental representation in the two theories is discussed at length in Spencer and Schöner and Munakata and McClelland (this issue).

\section{(7) Mental representations}

Of the four classic developmental theories, Gibson is clearly least concerned with the mentalistic aspects of developmental change. Her emphasis on perception and action follows J.J. Gibson's well-known critique of the 'new' cognitive psychology, with its emphasis on various stages of information processing. J.J. Gibson argued that much of this theoretical apparatus was superfluous, and that much of the structure attributed to sundry buffers and operators inside the mind was really coming from the active process of behaving in a structured world, a world which could be accessed directly. Gibson's ideas had a strong influence on initial works within dynamic systems theory as it was first applied to behavioral development (especially motor development). This emphasis on structure outside the organism led to a de-emphasis on the structures that are building up inside the organism. As a result, Thelen and Smith's two books in 1994 focused more on behavior than the contents of mind - a flavor that appears to set them at odds with connectionist research and all its emphases on hidden layers and the emergence of distributed representations 'inside the box'. In fact, in the first version of Table 1 (as presented at SRCD in 2001), Bates placed a brisk 'NO' for dynamic systems in the category 'emphasis on mental representations', compared with a clear 'YES' for connectionism. In the current version of Table 1, we have changed that notation to read 'NO until after 1994' (see Spencer \& Schöner, this issue), because, in fact, there is no incompatibility between dynamic systems theory and the exploration of mental structures. (Indeed dynamic systems theorists like van Geert (1994) and Bidell \& Fischer (2000) focus largely on mental structures.) The difference has been really a matter of emphasis: should the dynamics reflect behavior or the workings of mind?

\section{(8) Dynamic systems}

Dynamic systems as a theory of development represents an effort to implement insights from dynamic systems theory in physics, mathematics and biology. This is, in short, the very core of the enterprise. Because dynamic systems is itself a late 20th century movement, it is not 
surprising that these ideas had little influence on the four classic developmental theories. However, modern-day Gibsonians like Turvey, Kelso and Shaw (Kelso, 1995; Turvey, 1977; Turvey, Mace \& Shaw, 1978) have been pioneers in using dynamic systems to explain aspects of perceptual and motor functioning in adult humans. The real question here regards the role of dynamic systems in connectionism: is there one? The answer is absolutely YES. By their very nature, nonlinear neural networks are nonlinear dynamical systems (see especially Elman et al., 1996, Chapter 4); they embody the principles and phenomena that define dynamic systems theory, although not all practitioners of connectionism are aware of the extent to which this is the case. There is admittedly a difference in emphasis: dynamic systems have emphasized the entire coalitional contributions to behavior, while connectionism has been concerned with changes in mental representations. Nonetheless, connectionism and dynamic systems share, at base, the very same ideas about the nonlinear dynamics of change, sensitivity to initial conditions and the sudden catastrophic transformations (including U-shaped behaviors) that can take place after gradual increments along some quantitative parameter. This is indeed one of the most important respects in which we have come to believe that we are working with the same theory.

\section{(9) Mathematical formalisms}

Chomsky's theory of language and language development has been formalized since its incipience, starting with Chomsky's early work on a hierarchy of possible natural and artificial languages (based on the assumption that all languages constitute strings of symbols and operations for combining symbols). There was no such formal dimension to Gibson's theory, nor did Vygotsky invoke mathematical notation to represent social structures and their internalization by the child. In contrast, Piaget spent much of his career seeking a satisfactory set of mathematical terms to formalize his insights into the development of logic, from spatial logic at the sensorimotor level to the higher logic of formal operations. These particular formats have not outlived their author; they play little role in developmental psychology today, and (in contrast to much of Piaget's creative work) are regretted by few.

Formalization has played an important role in both dynamic systems theory and connectionism, but for the most part these formalizations have been directed at different levels. Many of the key examples in the two volumes by Smith and Thelen pertain to formalization at the level of behavior (e.g. the dynamics of moving from walking to running). In contrast, mathematical formal- isms have been applied by connectionists to the architecture and function of the learning device itself, at a level that corresponds more to mind than behavior. Reflecting this difference, the first version of Table 1 (as presented by Bates in 2001) contained a 'NO' under formalization for dynamic systems and a 'YES' under connectionism. Upon reflection and discussion, we concluded that this was simply a mistake. Mathematics plays a central role in both theories. The future extensions of these developmental theories will necessarily rely heavily on input from physicists and mathematicians who are especially comfortable with this aspect of the work in close collaboration with theorists and experimentalists like Bates and Thelen, who are not mathematicians.

\section{(10) Computer simulations}

Computer simulations are formalizations in their own right, and can always be described mathematically. However, not all formalizations are implemented in computer simulations. If the formalization is simple enough, then an implementation in a computer simulation may constitute nothing more than showing off (unless of course that implementation is the working end of a serious and useful application, e.g. speech recognition or robotics). But many formalisms (especially within dynamic systems) are simply much too complex to work through entirely on paper. To understand how a complex formalism really works (i.e. what outputs it gives, under various inputs), computer simulations are playing an increasingly important role - not just in psychology, but in physics, meteorology, oceanography and various other domains of 'hard' science. With a few interesting exceptions, developmentalists working within Chomsky's theory have not found computer simulations very useful. Gibson, Vygotsky and Piaget were all working in a time before computer simulation was an option - although we suspect that Piaget would have loved these tools if they had been available to him.

Prior to 1994, there were relatively few examples of computer-simulated formalisms within the body of work summarized by Thelen and Smith. By contrast, simulations are the lifeblood of the connectionist movement, and cognitive science students working with connectionist models often have to be reminded to gain expertise in the behavioral and biological phenomena that they are trying to model. Although the undersigned have never conducted simulations of their own, Thelen and Bates are avid consumers of modeling efforts in developmental psychology. We simply want to remind our students and colleagues that progress is more likely when the models are responsive to real behavioral and biological data. The best of both worlds is obtained when modeling and 
behavioral work are in a dialogue (preferably within the same brain, but at least within the same collaboration): the model suggests new experiments, the experiments suggest new models, and the two techniques proceed together, each profiting from the other. This is certainly one of the most important respects in which connectionism and dynamic systems are working the same side of the street.

\section{Conclusion}

We said at the beginning of this article that it is not the particular form of a model that is important, but the general theoretical assumptions that motivate the model. Based on the theoretical taxonomy in Table 1, and our own discussions of it, we have reached the conclusion that connectionism and dynamic systems are not competing theories of development. The two approaches have somewhat different histories. Dynamic systems has emerged primarily from the field of perception-action, and has had its greatest impact in early sensorimotor development. Connectionism arose from computational modeling and focuses largely on the internal mappings of the brain and its representational contents. Their practitioners continue to differ in their preferred methodologies and research questions. But at a more general theoretical level, there are far more shared assumptions than real differences. They are both really two aspects of a new, synthetic theory of development that unites insights from developmental neurobiology, physics, mathematics and computer science in the service of an increased understanding of human development. Without undue strain on the metaphor with which we began this introduction, we see our boat as not 'pre-paradigmatic' at all, but a sturdy vessel built upon the hull of Piaget and fitted out with theory and tools for a long and successful voyage.

\section{References}

Amari, S. (1977). Dynamics of pattern formation in lateralinhibition type neural fields. Biological Cybernetics, 27, 7787.

Bastian, A., Riehle, A., Erlhagen, W., \& Schöner, G. (1998). Prior information preshapes the population representation of movement direction in motor cortex. NeuroReport, 9, 315-319.

Bates, E. (1976). Language and context: The acquisition of pragmatics. New York: Academic Press. (Paperback edition issued 1980.)

Bates, E. (Ed.) (1991). Special issue: cross-linguistic studies of aphasia. Brain \& Language, 41 (2).
Bates, E., with Benigni, L., Bretherton, I., Camaioni, L., \& Volterra, V. (1979). The emergence of symbols: Cognition \& communication in infancy. New York: Academic Press.

Bates, E., Bretherton, I., \& Snyder, L. (1988). From first words to grammar: Individual differences and dissociable mechanisms. New York: Cambridge University Press. (Paperback edition issued 1991.)

Bates, E., Camaioni, L., \& Volterra, V. (1975). The acquisition of performatives prior to speech. Merrill-Palmer Quarterly, 21 (3), 205-226. (Reprinted in E. Ochs \& B. Schieffelin (Eds.), Developmental pragmatics. New York: Academic Press, 1979, pp. 111-128; Reprinted in A. Kasher (Ed.), Pragmatics: Critical concepts. London: Routledge, 1998, pp. 274-295.)

Bates, E., \& Elman, J. (2002). Connectionism and the study of change. In M. Johnson (Ed.), Brain development and cognition: a reader (2nd edn.). Oxford: Blackwell Publishers. (Revised/updated/extended version of Bates, E., \& Elman, J. Connectionism and the study of change. In M. Johnson (Ed.), Brain development and cognition: A reader. Oxford: Blackwell Publishers, 1993, pp. 623-642.)

Bates, E., \& Goodman, J. (1997). On the inseparability of grammar and the lexicon: evidence from acquisition, aphasia and real-time processing. In G. Altmann (Ed.), Special issue on the lexicon, Language and Cognitive Processes, 12 (5/6), 507-586.

Bates, E., Thal, D., \& Marchman, V. (1991). Symbols and syntax: a Darwinian approach to language development. In N. Krasnegor, D. Rumbaugh, R. Schiefelbush \& M. StuddertKennedy (Eds.), Biological and behavioral determinants of language development (pp. 29-65). Hillsdale, NJ: Erlbaum.

Bates, E., Thal, D., Trauner, D., Fenson, J., Aram, D., Eisele, J., \& Nass, R. (1997). From first words to grammar in children with focal brain injury. In D. Thal \& J. Reilly (Eds.), Special issue on origins of communication disorders. Developmental Neuropsychology, 13 (3), 447-476.

Bernstein, N. (1967). The coordination and regulation of movements. Oxford: Pergamon.

Bidell, T.R., \& Fischer, K.W. (2000). The role of cognitive structure in the development of behavioral control: a dynamic skills approach. In W.J. Perrig \& A. Grob (Eds.), Control of human behavior, mental processes, and consciousness: Essays in honor of the 60th birthday of August Flammer (pp. 183-201). Mahwah, NJ: Lawrence Erlbaum Associates.

Chomsky, N. (1968). Language and mind. New York: Brace \& World.

Chomsky, N. (1975). Reflections on language. New York: Pantheon Books.

Chomsky, N. (1988). Language and problems of knowledge: The Managua lectures. Cambridge, MA: MIT Press.

Dick, F., Bates, E., Wulfeck, B., Utman, J., Dronkers, N., \& Gernsbacher, M. (2001). Language deficits, localization and grammar: evidence for a distributive model of language breakdown in aphasics and normals. Psychological Review, 108 (4), 759-788.

Elman, J.L., Bates, E.A., Johnson, M.H., Karmiloff-Smith, A., Parisi, D., \& Plunkett, K. (1996). Rethinking innateness: A connectionist perspective on development. Cambridge, MA: MIT Press. 
Fodor, J.A. (1983). The modularity of mind. Cambridge, MA: MIT Press.

Forssberg, H. (1985). Ontogeny of human locomotor control. I. Infant stepping, supported locomotion, and transition to independent locomotion. Experimental Brain Research, 57, 480-493.

Gibson, E.J. (1969). Principles of perceptual learning and development. Englewood Cliffs, NJ: Prentice-Hall.

Gibson, E.J. (1988). Exploratory behavior in the development of perceiving, acting, and the acquiring of knowledge. Annual Review of Psychology, 39, 1-41.

Gibson, J.J. (1979). The ecological approach to visual perception. Boston: Houghton Mifflin.

Gopnik, A. (1996). The post-Piaget era. Psychological Science, 7 (4), 221-225.

Greene, P.H. (1982). Why is it easy to control your arms? Journal of Motor Behavior, 14, 260-286.

Haken, H. (1977). Synergetics: An introduction. Heidelberg: Springer-Verlag.

Kelso, J.A.S. (1995). Dynamic patterns: The self-organization of brain and behavior. Cambridge, MA: MIT Press.

Kelso, J.A.S., Holt, K.G., Kugler, P.N., \& Turvey, M.T. (1980). On the concept of coordinative structures as dissipative structures: II. Empirical lines of convergence. In G.E. Stelmach \& J. Requin (Eds.), Tutorials in motor behavior (pp. 49-70). New York: North-Holland.

Koch, C., \& Davis, J.L. (Eds.) (1994). Large-scale neuronal theories of the brain. Cambridge, MA: MIT Books.

Kugler, P., Kelso, J.A.S., \& Turvey, M.T. (1980). On the control and coordination of naturally developing systems. In J.A.S. Kelso \& J.E. Clark (Eds.), The development of movement control and coordination (pp. 5-78). New York: John Wiley.

Lewis, M.D., Lamey, A.V., \& Douglas, L. (1999). A new dynamic systems method for the analysis of early socioemotional development. Developmental Science, 2, 457-475.

MacWhinney, B., \& Bates, E. (Eds.) (1989). The crosslinguistic study of sentence processing. New York: Cambridge University Press.

Piaget, J. (1896). Comments on Vygotsky's critical remarks concerning The language and thought of the child, and Judgment and reasoning in the child. Cambridge, MA: MIT Press, 1962.

Piaget, J. (1952). The origins of intelligence in children. New York: International Universities Press.

Piaget, J. (1970). Genetic epistemology. New York: Columbia University Press.

Port, R.F., \& van Gelder, T. (1995). Mind as motion: Explorations in the dynamics of cognition. Cambridge, MA: MIT Press.

Rumelhart, D., \& McClelland, J.L. (Eds.) (1986). Parallel distributed processing: Explorations in the microstructure of cognition. Vol. 1. Foundations. Cambridge, MA: MIT Press.

Smith, L.B., \& Thelen, E. (Eds.) (1993). A dynamic systems approach to development: Applications. Cambridge, MA: MIT Press.

Smith, L.B., Thelen, E., Titzer, R., \& McLin, D. (1999). Knowing in the context of acting: the task dynamics of the A-not-B error. Psychological Review, 106, 235-260.

Sporns, O., \& Edelman, G.M. (1993). Solving Bernstein's prob- lem: a proposal for the development of coordinated movement by selection. Child Development, 64, 960-981.

Thelen, E. (1979). Rhythmical stereotypies in normal human infants. Animal Behaviour, 27, 699-715.

Thelen, E. (1981). Rhythmical behavior in infancy: an ethological perspective. Developmental Psychology, 17, 237-257.

Thelen, E. (1985). Developmental origins of motor coordination: leg movements in human infants. Developmental Psychobiology, 18, 1-22.

Thelen, E. (1986). Treadmill-elicited stepping in seven-monthold infants. Child Development, 57, 1498-1506.

Thelen, E., Corbetta, D., \& Spencer, J.P. (1996). The development of reaching during the first year: the role of movement speed. Journal of Experimental Psychology: Human Perception and Performance, 22, 1059-1076.

Thelen, E., \& Fisher, D.M. (1982). Newborn stepping: an explanation for a 'disappearing' reflex. Developmental Psychology, 18, 760-775.

Thelen, E., \& Fisher, D.M. (1983). The organization of spontaneous leg movements in newborn infants. Journal of Motor Behavior, 15, 353-377.

Thelen, E., Schöner, G., Scheier, C., \& Smith, L.B. (2001). The dynamics of embodiment: a dynamic field theory of infant perseverative reaching errors. Behavioral and Brain Sciences, 24, 1-86.

Thelen, E., \& Smith, L.B. (1994). A dynamic systems approach to the development of cognition and action. Cambridge, MA: MIT Press.

Thelen, E., \& Ulrich, B.D. (1991). Hidden skills: a dynamical systems analysis of treadmill stepping during the first year. Monographs of the Society for Research in Child Development, 56, No. 223.

Thompson, D'Arcy W. (1942). On growth and form. Cambridge: The University Press.

Turvey, M.T. (1977). Preliminaries to a theory of action with reference to vision. In R. Shaw \& J. Bransford (Eds.), Perceiving, acting, and knowing: Toward an ecological psychology (pp. 211-265). New York: Wiley.

Turvey, M.T., Shaw, R., \& Mace, W. (1978). Issues in a theory of action: degrees of freedom, coordinative structures and coalitions. In J. Requin (Ed.), Attention and performance VII (pp. 557-595). Hillsdale, NJ: Erlbaum.

Van der Maas, H.L.J., \& Molenaar, P.C.M. (1992). Stagewise cognitive development: an application of catastrophe theory. Psychological Review, 99, 395-417.

Van Geert, P. (1994). Dynamic systems of development: Change between complexity and chaos. New York: Prentice-Hall.

Van Geert, P. (1998). A dynamic systems model of basic developmental mechanisms: Piaget, Vygotsky, and beyond. Psychological Review, 105, 634-677.

Vygotsky, L.S. (1978). Mind in society: The development of higher psychological processes. Cambridge, MA: Harvard University Press.

Wolff, P.H. (1968). Stereotypic behavior and development. Canadian Psychologist, 9, 474-483.

Yoshikawa, H., \& Hsueh, J. (2001). Child development and public policy: towards a dynamic systems perspective. Child Development, 72, 1887-1903. 